\title{
Optimization of the entrapment efficiency and release of ambroxol hydrochloridealginate beads
}

\author{
Karam F. Abdalla ${ }^{1 *}$, Elabadawy A. Kamoun ${ }^{2}$, Gamal M. El Maghraby ${ }^{1}$ \\ ${ }^{1}$ Department of Pharmaceutical Technology, College of Pharmacy, University of Tanta, Tanta, Egypt. \\ ${ }^{2}$ Department of Polymeric Materials, City of Scientific Research and Technological Applications, Alexandria, Egypt.
}

\section{ARTICLE INFO \\ Article history: \\ Received on: 18/01/2015 \\ Revised on: 09/02/2015 \\ Accepted on: 22/02/2015 \\ Available online: 27/04/2015}

Key words:

alginate beads; specification; viscosity modifiers; E.E; release.

\begin{abstract}
The objective of the current study was to optimize the composition of alginate beads to produce ambroxol hydrochloride alginate beads with optimum specifications. The study employed beads based on sodium alginate solution $(2 \% \mathrm{w} / \mathrm{v})$ as the main component with calcium chloride solution as crosslinking agent as the prototype beads. The beads were prepared by syringe method. The effect of viscosity modifiers on the morphology, entrapment efficiency and drug release was studied. The prototype beads were spherical semitransparent with entrapment efficiency (EE) of 23\%. Incorporation of polyvinylpyrrolidone (PVP) as a viscosity modifier produced spherical semitransparent beads with higher EE values compared with the prototype. Addition of carboxymethyl cellulose (CMC) produced oval opaque beads which have larger size and higher EE values compared with the prototype beads or those containing PVP only. Replacement of CMC with hydroxypropyl methyl cellulose (HPMC) produced semitransparent spherical beads with significant increase in the EE. Monitoring the drug release rate from different beads, the all the tested beads were able to retain the drug in the stomach condition. In the intestinal conditions the release rate depended on the composition of the beads with prototype beads librating most of its contents in the first 15 minutes. Formulations containing either CMC or HPMC were able to retard the drug release in the intestinal phase. In conclusion the study developed beads with optimum entrapment and release of ambroxol hydrochloride.
\end{abstract}

\section{INTRODUCTION}

Alginate is a polysaccharide which contains varying amounts of 1,4'-linked $\beta$-D-mannuronic acid, $\alpha$-L-guluronic acid residues. As biocompatible and biodegradable biopolymer, it can form a bioadhesive stable gel especially in the presence of divalent cations such as calcium or barium. These properties have been employed in development of controlled release drug delivery system (Rasel and Hasan, 2012). Sodium alginate has been tested for sustained and controlled oral delivery of drugs with no evidence for mucosal damage (Kanjanabat and Pongjanyakul, 2011; Rajesh et al., 2012). The effect of divalent cations on alginate solution is widely used in preparation of solid beads for controlled drug delivery (Kanaka Durga Devil et al., 2010). These beads are acid resistant and can liberate the drug slowly in acidic environment. Ionotropic gelation technique

* Corresponding Author

Mail id: karamfawzyabdalla@gmail.com
(Poncelet et al., 1999) is the most widely used technique with the majority of researchers employing syringes manually or mechanically via pump to simply drip alginate solution into a solution of divalent cation. This is expected to form beads (Takka and Gürel, 2010). This strategy is considered traditional and is being modified in many ways to control the size and shape of the beads. The major problem in preparation of beads is poor entrapment of hydrophilic drugs which tend to escape to the external aqueous environment during the process of beads production. Taking into consideration the fact that the majority of drug candidates requiring controlled release delivery systems are hydrophilic, it is important to optimize the entrapment efficiency of these drugs into the beads. The characteristics of beads depend on the composition of alginate based system. Addition of other excepients can affect size, shape, entrapment efficiency and release of drugs from such beads (Rangaraj et al., 2010). Accordingly the objective of the current study was to optimize the composition of alginate beads to produce beads with optimum specifications. To achieve this Ambroxol $\mathrm{HCl}$ was selected as model drug. Ambroxol is an active metabolite of the mucolytic agent bromhexine and is 
used in the treatment of bronchitis to improve expectoration. It is rapidly absorbed after oral administration followed by rapid elimination requiring three doses per day for optimum therapeutic efficacy (Kubo et al., 2004). The effect of viscosity modifiers such as hydroxypropyl methylcellulose (HPMC), sodium carboxy methylcellulose (NaCMC) and Polyvinyl pyrrolidone (PVP) on the characteristics of beads was investigated.

\section{MATERIALS AND METHODS}

\section{Materials}

Ambroxol was obtained as gift sample from Pharco pharmaceuticals, Alexandria. Sodium alginate (AR grade) was purchased from M.P. Biomedicala, LLC, France. Calcium Chloride was purchased from Al-Nasr Chemical Company, Cairo Egypt. Hydroxypropyl methylcellulose (HPMC E5) was supplied as a gift sample from Sigma pharmaceutical industries, Egypt. Polyvinyl pyrrolidone (PVP K30) was purchased from Sigma Chemical Company, St. Louis, USA. Sodium carboxy methylcellulose (CMC) was purchased from Nice Chemicals, Kerala, India. All other chemicals used in the present study were of analytical grade.

\section{Spectrophotmetric determinations}

The concentrations of ambroxol hydrochloride were determined by UV Spectrophotometry. This employed a spectrophotometer, Thermo Fisher Scientific, USA. Determinations were performed at $248 \mathrm{~nm}$ and the calibration curve was linear $\left(\mathrm{R}^{2}\right.$ $=0.9975)$ in the concentration range of $12-40 \mu \mathrm{g} / \mathrm{ml}$.

\section{Preparation of drug- loaded beads by manual syringe method}

The beads were prepared according to the composition presented in Table 1. Sodium alginate was dissolved in distilled water at $60^{\circ} \mathrm{C}$ under magnetic stirring for 2 hours in order to obtain $100 \mathrm{ml}$ of polymer solution with concentration of $2 \%(\mathrm{w} / \mathrm{w})$. HPMC or CMC were dispersed in the alginate solution if required. This was achieved by sprinkling the polymer powder on the surface of the alginate solution while stirring. The specification of beads prepared by this method depends on the inner diameter of the needle. Accordingly, $10 \mathrm{ml}$ syringes fitted with a needle having a size of $21 \mathrm{G}$ were employed in preparation of all formulation. Sodium alginate solution $(2 \% \mathrm{w} / \mathrm{v})$ in presence or absence of other polymers with drug being solubilized in was introduced drop wise into the gelling solution $(2 \% \mathrm{w} / \mathrm{v}$ aqueous calcium chloride with or without viscosity modifier, Table 1 ) while being gently stirred at $25^{\circ} \mathrm{C}$. The stirring was continued for 15 minutes and the calcium alginate beads were harvested by filtration (Badarinath et al., 2010).

\section{Determination of entrapment efficiency and drug content}

The entrapment efficiency of the drug into the beads was determined after separation of the beads from the free drug remaining in solution. The entrapment efficiency (EE) was calculated using the equation:

\section{$\mathrm{EE}(\%)=[($ Total drug added - amount of free drug $) /$ total drug added] x 100}

The drug content in the beads was determined by crushing known amount of dry beads a mortar with a pestle before soaking in $100 \mathrm{ml}$ of phosphate buffer ( $\mathrm{pH}$ of 7.4) with continuous stirring using overhead stirrer for 60 minutes. This provided complete swelling and bursting of the beads. The resultant dispersion was filtered through $0.45 \mu \mathrm{m}$ membrane filter and the concentration of drug in the solution was determined spectrophotometrically after appropriate dilution using phosphate buffer (pH of 7.4) (Narra et al., 2012).

The drug content was calculated as the percentage drug load was given by the formula:

$$
\% \text { Drug load }=(\mathrm{WD} / \mathrm{WB}) \times 100
$$

Where, WD is the amount of drug loaded in beads and WB is the weight of beads.

\section{Particle morphology and particle size measurement}

The beads were placed on a dark background and were photographed in presence of the measuring meter using a digital camera. The bead size was measured using Microsoft Powerpoint software with the taking the measuring meter as the reference scale. The average size of 50 beads was recorded (Mandal et al., 2010).

The average diameter of the beads was calculated using the following formula:

$\mathrm{X}=\sum\left(\mathrm{X}_{\mathrm{i}}\right) / \mathrm{N}$

$\mathrm{X}=$ Average particle diameter, $\mathrm{Xi}=$ Individual diameter of beads, $\mathrm{N}=$ Number of beads.

\section{Determination of dissolution rate}

In vitro release studies of prepared microbeads were carried out using USP type 2 dissolution (paddle method) apparatus at $50 \mathrm{rpm}$. The release studies were performed in both stomach and intestinal environment. The stomach phase was conducted for 2 hours during which the drug release was monitored in $0.1 \mathrm{~N} \mathrm{HCl}$. For the intestinal phase, the release study was conducted for a total period of 6 hours using $900 \mathrm{ml}$ of phosphate buffer ( $\mathrm{pH}$ 6.8) for first 4 hours at the end of which the $\mathrm{pH}$ was adjusted using $1 \mathrm{~N}$ sodium hydroxide solution to 7.4 and the release was continued for the rest of the period. The temperature of the dissolution medium was maintained at $37 \pm 1^{\circ} \mathrm{C}$. At periodic time intervals, $5 \mathrm{ml}$ of samples were withdrawn, filtered immediately and drug content was determined spectrophotometrically at $248 \mathrm{~nm}$. Fresh dissolution media $(5 \mathrm{ml})$ was added each time to compensate the dissolution medium. The cumulative percentage of drug release was plotted as a function of time to create the release profile. This was used to calculate the release efficiency (RE) which was calculated from the area under the release curve at time $t$ (determined using the non-linear trapezoidal rule) and expressed as a percentage of the area of the rectangle described by $100 \%$ release in the same time (El Maghraby and Alomrani, 2009). 
Table 1: The composition of the tested formulations.

\begin{tabular}{|c|c|c|c|c|c|c|}
\hline \multirow{2}{*}{$\begin{array}{l}\text { Formula } \\
\text { code }\end{array}$} & \multirow{2}{*}{$\begin{array}{c}\text { sodium alginate } \\
(\% \mathrm{w} / \mathrm{v})\end{array}$} & \multirow{2}{*}{$\begin{array}{c}\text { Drug } \\
(\% \mathrm{w} / \mathrm{v})\end{array}$} & \multirow{2}{*}{$\begin{array}{c}\text { Crosslinking agent } \\
\mathrm{Ca} \mathrm{Cl2}(\% \mathrm{w} / \mathrm{v})\end{array}$} & \multicolumn{3}{|c|}{$\begin{array}{l}\text { Viscosity modifiers agent } \\
\end{array}$} \\
\hline & & & & $\operatorname{PVP}(\% \mathrm{~W} / \mathrm{V})$ & $\mathrm{Na} \mathrm{CMC}$ & HPMC \\
\hline F1 & $2 \%$ & $0.50 \%$ & $2 \%$ & 0 & 0 & 0 \\
\hline $\mathrm{F} 2$ & $2 \%$ & $0.50 \%$ & $2 \%$ & $2 \%$ & 0 & 0 \\
\hline F3 & $2 \%$ & $0.50 \%$ & $2 \%$ & $3 \%$ & 0 & 0 \\
\hline $\mathrm{F} 4$ & $2 \%$ & $0.50 \%$ & $2 \%$ & $4 \%$ & 0 & 0 \\
\hline F5 & $2 \%$ & $0.50 \%$ & $2 \%$ & $2 \%$ & $1 \%$ & 0 \\
\hline F6 & $2 \%$ & $0.50 \%$ & $2 \%$ & $2 \%$ & $2 \%$ & 0 \\
\hline F7 & $2 \%$ & $0.50 \%$ & $2 \%$ & $2 \%$ & $3 \%$ & 0 \\
\hline F8 & $2 \%$ & $0.50 \%$ & $2 \%$ & 0 & $2 \%$ & 0 \\
\hline F9 & $2 \%$ & $0.50 \%$ & $2 \%$ & $2 \%$ & 0 & $0.50 \%$ \\
\hline F10 & $2 \%$ & $0.50 \%$ & $2 \%$ & $2 \%$ & 0 & $1 \%$ \\
\hline F11 & $2 \%$ & $0.50 \%$ & $2 \%$ & $2 \%$ & 0 & $2 \%$ \\
\hline
\end{tabular}

Table 2: The characteristics of the prepared beads

\begin{tabular}{|c|c|c|c|c|}
\hline Formula code & Entrapment efficiency (\%) & Particle size $(\mu \mathrm{m})$ & Drug cotent $(\%)$ & Release efficiency (\%) \\
\hline $\mathrm{F} 1$ & $23 \pm 0.43$ & $2000 \pm 0.001$ & $2 \pm 0.08$ & $91 \pm 1.34$ \\
\hline $\mathrm{F} 2$ & $25.66 \pm 0.19$ & $2022 \pm 133$ & $2.4 \pm 0.04$ & $78.39 \pm 1.67$ \\
\hline F3 & ND & $2035 \pm 145$ & ND & ND \\
\hline F4 & $26.85 \pm 0.54$ & $2041 \pm 151$ & ND & ND \\
\hline F5 & $27.43 \pm 2.11$ & $2747 \pm 252$ & ND & ND \\
\hline F6 & $38.54 \pm 0.31$ & $2770 \pm 227$ & $3.94 \pm 0.04$ & $69.66 \pm 0.26$ \\
\hline F7 & $29.07 \pm 0.26$ & $2793 \pm 220$ & ND & ND \\
\hline F8 & $29.9 \pm 1.91$ & $3133 \pm 48$ & $2.81 \pm 0.06$ & $75.92 \pm 1.01$ \\
\hline F9 & $29.23 \pm 0.36$ & $2062 \pm 295$ & ND & ND \\
\hline F10 & $46.86 \pm 0.32$ & $2069 \pm 302$ & ND & ND \\
\hline F11 & $53.73 \pm 0.15$ & $2078 \pm 341$ & $4.54 \pm 0.09$ & $65.93 \pm 0.65$ \\
\hline
\end{tabular}

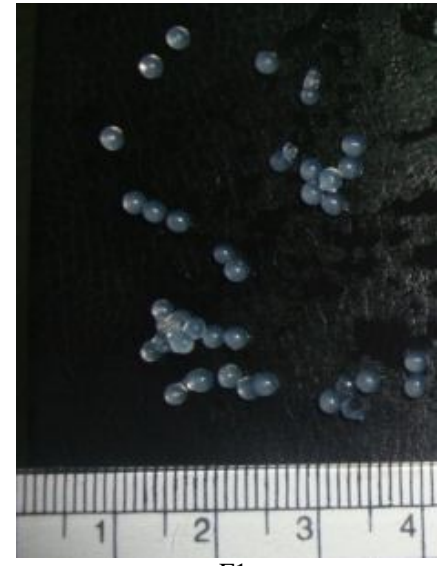

F1

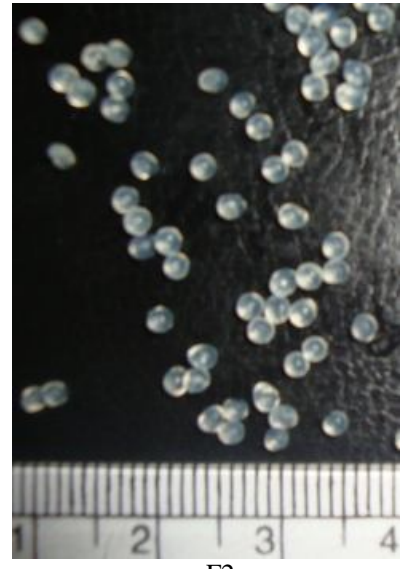

F2

Fig. 1: Photographs of sodium alginate beads in absence and presence of increasing concentrations of PVP as viscosity modifier. Formulation details are in Table 1 .
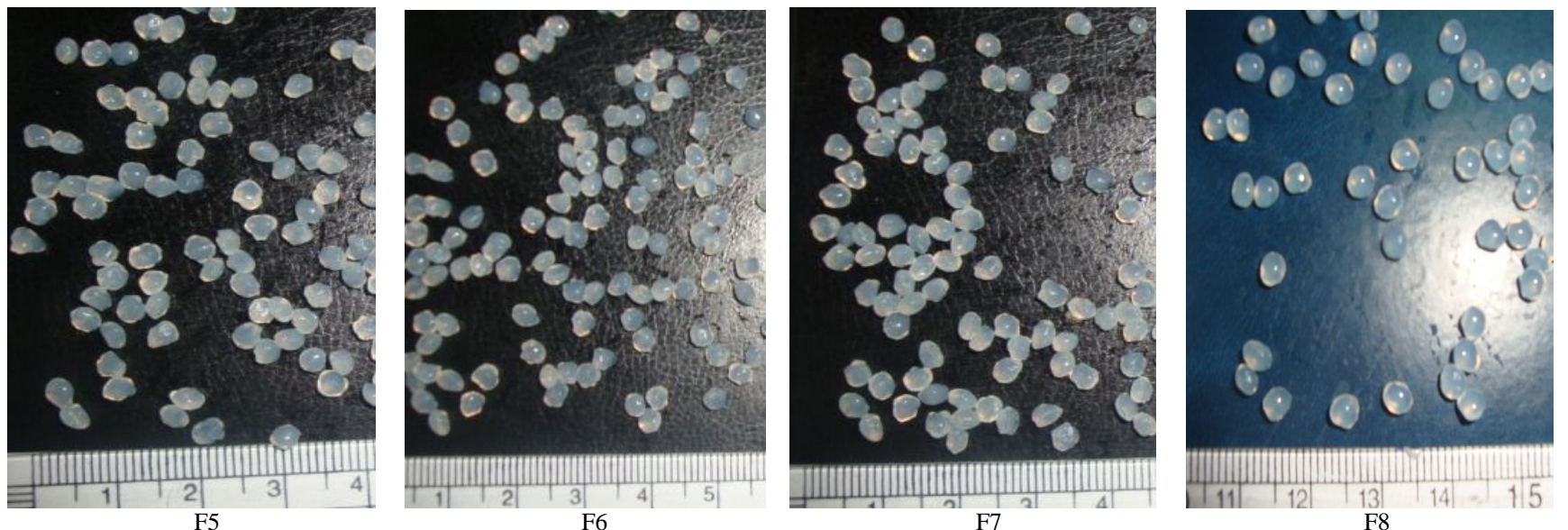

Fig. 2: Photographs of sodium alginate beads in presence carboxymethyl cellulose as hydrophilic polymer. Formulation details are in Table 1. 


\section{RESULTS AND DISCUSSION}

\section{Beads preparation}

The aim of this study is to optimize the composition of alginate beads to produce beads with optimum specifications and to study the effect of viscosity modifiers such as hydroxypropyl methylcellulose (HPMC), sodium carboxy methylcellulose (CMC) and polyvinyl pyrrolidone (PVP) on the characteristics of beads.

The crosslinking time was shown to be an important factor in preparation of beads. Increasing the crosslinking time was shown to decrease the drug entrapment efficiency, since prolonged exposure in the curing medium caused greater loss of drug through crosslinked alginate microsphere (Kassem et al., 2012). Accordingly, the crosslinking time was kept constant (15 minutes) in all formulations. This was done to exclude any source of variability due to any variation in crosslinking time. The stirring rate during crosslinking is believed to be a determining factor that affects the bead size and the yield with very high stirring rate being responsible for reduction in the yield (Al-kassas et al., 2007). Accordingly, the stirring rate was kept at $400 \mathrm{rpm}$ and was maintained with all formulation. This ensures that any variation in the bead size or morphology will be due to the variation in the composition.

The prepared beads were compared with respect to their morphology, size and entrapment efficiency of drug. The morphology of the prepared beads is shown in Figures and measured parameters are presented in Table 2. The standard alginate beads which were prepared in absence of any polymer (F1) were spherical and semitransparent in appearance (Figure 1). The particle size of these beads was $2000 \mu \mathrm{m}$ and the beads were homogenous as reflected from the very low standard deviation values. The homogeneity of the beads is expected as the alginate solution was dropped on the calcium chloride solution at fixed rate with the droplet size being constant. Similar data was recorded using the same formulation (Arica et al., 2002; Chan et al., 2009). Incorporation of PVP as a viscosity modifier in the crosslinking solution produced spherical beads which were semitransparent with marginal increase in the bead size compared with the standard beads (Figure 1 and Table 2). PVP is known to block the pores of alginate beads suggesting that most of the polymer will be intercalated within these pores with minute amounts being adsorbed on the surface of the beads. This may explain the recorded marginal increase in the bead size after incorporation of PVP in the crosslinking solution (Narra et al., 2012). Incorporation of CMC in the alginate solution resulted in relatively opaque beads with the beads loosing their spherical appearance with significant increase in the bead size compared with the standard bead or those prepared in presence of PVP as a viscosity modifier (Figure 2 and Table 2). The loss in the spherical nature of the beads can be explained on the bases that addition of CMC resulted in significant increase in the viscosity of alginate solution with the results that the falling droplets became non-spherical. This effect was associated with increased droplet size with subsequent increase in the bead size after crosslinking. The opacity of the beads can be explained on the base of the crosslinking effect of calcium on CMC with the later being expected to precipitate in presence of calcium. Similar increase in bead size was recorded after incorporation of CMC in the working solution and was explained on the base of increased viscosity (Saleem et al., 2012). Replacing CMC with HPMC E5 produced beads which retained their spherical appearance and were less opaque compared with those prepared in presence of CMC. The size of the beads was significantly smaller than that of the beads containing CMC but was relatively larger than that of the standard beads or the corresponding beads which were prepared in presence of PVP only (F2), (Figure 3 and Table 2). Considering the low viscosity of the tested HPMC E5, the recorded difference between HPMC based beads and CMC based beads confirm the previous explanation which suggested that the thickening effect of CMC was responsible for the increased particle size of CMC based beads. With respect to the absence of opacity in case of HPMC, it can be due to the lack of interaction between calcium ions and HPMC. It should be noted that, the presence of very high concentration of HPMC (30\%) in alginate solution was previously shown to produce irregular structure due to the high content of HPMC in the blend which hindered the effective physical crosslinking. This can result in a situation where part of the material is washed out from the beads with subsequent collapse of the structure (Karewicz et al., 2010). This phenomenon was not recorded in the current study as the tested HPMC grade was of low viscosity with the maximum concentration being maintained at $2 \%$.

\section{Entrapment efficiency and drug content}

The ability of beads to entrap the drug is the determining factor for selection of the method of preparation and composition of the beads. Accordingly, the effect of bead composition on the entrapment efficiency and drug content was investigated. Table 2 presents the results of entrapment efficiency and drug content in the beads. The standard beads which utilized sodium alginate as the bead former with calcium chloride as the crosslinking agent in absence of any viscosity modifier was able to entrap $23 \%$ of the drug.

The drug content of the solid beads was only $2 \% \mathrm{w} / \mathrm{w}$. The low entrapment efficiency is expected taking into consideration the hydrophilic nature of the drug. This can lead to high potential for escaping from the beads before complete crosslinking. Incorporation of PVP in the crosslinking solution increased the entrapment efficiency of the drug to reach $25.66 \%$ with the drug content reaching $2.4 \%$ w/w on using $2 \%$ PVP in the crosslinking solution. Further increase in the concentration of PVP did not lead to significant increase in the drug loading (Table 2). Accordingly, 2\% PVP was utilized in further optimization of drug content. The recorded improvement in the drug loading in presence of PVP can be explained on the bases that PVP is capable of closing the surface pores in the beads with the result that the loss of drug being reduced during the crosslinking step. Similar finding was recorded and was explained on the same base (Narra et al., 2012). 


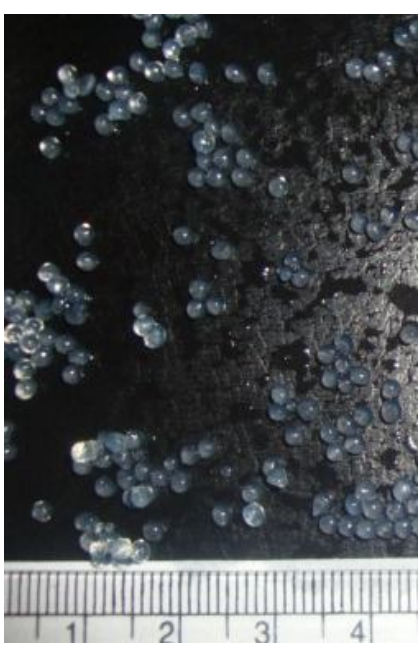

F9

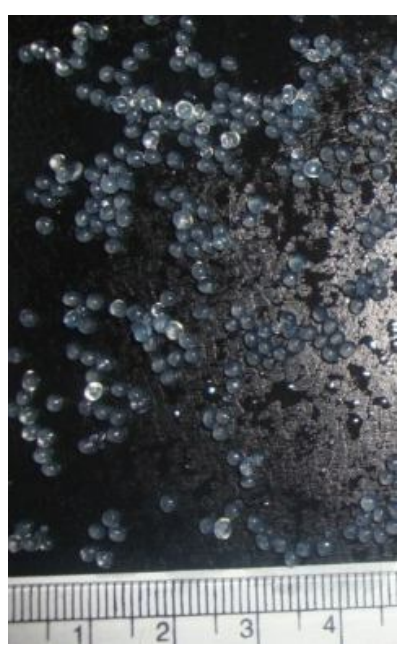

F10

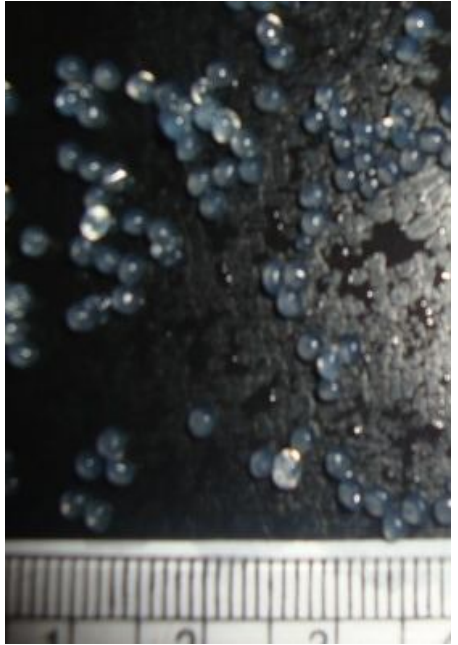

F11

Fig. 3: Photographs of sodium alginate beads in presence hydroxypropyl methylcellulose as hydrophilic polymer. Formulation details are in Table 1.

The study was extended to incorporate CMC with sodium alginate as a secondary bead former. This was conducted using calcium chloride/PVP solution for crosslinking. The presence of CMC resulted in significant increase in the entrapment efficiency and drug content. This was particularly evident in formulation containing $2 \%$ CMC. Preparing the same formulation in absence of PVP reduced the entrapment efficiency (Table 2). This suggests possible synergistic effect for PVP with CMC. The recorded improvement in the drug loading in presence of $\mathrm{CMC}$ can be explained on the bases that the presence of CMC enhanced the crosslinking efficiency as it can be precipitated with calcium which adds strength to the polymer chain crosslinking. Similar finding was recorded for the same polymer (Kassem et al., 2012). Reduction in drug loading in case of high concentration of CMC can be explained on the difficulty of obtaining proper spherical beads at high polymer concentration (Jelvehgari et al., 2014). This explains the need for optimum concentration of CMC. Replacing CMC with HPMC resulted in a significant increase in the drug loading with the entrapment efficiency reaching 53.73 and the drug content being $4.54 \% \mathrm{w} / \mathrm{w}$ in case of formulation containing $2 \%$ HPMC (Table 2). The recorded increase in the drug loading in presence of HPMC was previously explained on the base of formation of a more dense matrix structure (Goudanavar et al., 2010). Similar effect was recorded for hydroxyl propyl cellulose (Karewicz et al., 2010).

\section{Drug release}

The best formulation from each category was selected for release studies. The selected formulations included the prototype formulation which comprised sodium alginate with calcium chloride being the crosslinking solution $(\mathrm{F} 1)$, the formulation utilizing $2 \% \mathrm{w} / \mathrm{v}$ PVP as viscosity modifier (F2), the formulation containing alginate with $2 \% \mathrm{CMC}$ in the syringe and PVP and calcium chloride in the crosslinking solution (F6), the formulation containing alginate with $2 \% \mathrm{CMC}$ in the syringe and calcium chloride in the crosslinking solution (F8) and the formulation containing alginate with HPMC in the syringe and PVP with calcium chloride in the crosslinking solution (F11). The release profile was performed both in the acidic and intestinal environments. The release profiles are shown in Figure 4 and the calculated release efficiency values are presented in Table 2 . The amount of the drug released from the beads in the acidic environment (stomach conditions) was below the limit of quantification of the assay with the maximum recorded absorbance being around 0.14 . Taking into consideration the fact that the limit of quantification of the assay was $8 \mu \mathrm{g} / \mathrm{ml}$, it can be concluded that the amount of drug released from the beads is lower than $10 \%$ of the loaded drug in acid phase. In contrast the unprocessed drug powder was completely dissolved with the first hour. This is expected due to the poor solubility of calcium alginate beads in which the presence of calcium resulted in high degree of crosslinking in the acidic environment of the stomach (El Maghraby et al., 2012). Moving to the intestinal phase, the unprocessed drug powder librated more than $88 \%$ of the drug within 15 minutes with rest of the drug being dissolved after 30 minutes (Figure 4). Considering the beads the release in the intestinal phase depended on the composition of the beads. The prototype beads librated more than $70 \%$ of their contents in the first 15 minutes in the intestinal $\mathrm{pH}$. The release efficiency was 91\% (Table 2). Comparing the recorded release pattern of the drug from alginate beads in the intestinal phase with that recorded in the acid phase, it is clear that the former exhibited faster release compared with that recorded in the acidic environment. This can be explained on the bases of deprotonation of the alginate with subsequent disintegration of the beads (Narra et al., 2012, El Maghraby et al., 2012). To improve the ability of beads to retain drug, various hydrophilic polymers were included as a viscosity modifier. Incorporation of $2 \% \mathrm{w} / \mathrm{v}$ PVP in the crosslinking solution (F2) resulted reduced the drug release rate compared with the PVP-free formulation. This formulation librated $61 \%$ of its contents in the first 15 minutes in the intestinal phase with rest of the drug being librated slowly during the course of the study 
(Figure 4). The release efficiency was significantly reduced compared with F1 (Table 2). The recorded reduction in drug release in presence of PVP can be explained on the bases that PVP can block the surface pores of the beads and can form a 'pseudogel layer' surrounding the bead. This layer can hinder drug release from the surface of the beads (Narra et al., 2012). Another possible explanation for the recorded effect of PVP can be due to the formation intermolecular hydrogen-bonding between $\mathrm{C}=\mathrm{O}$ groups of PVP, and -OH groups of alginate in alginate-PVP $\mathrm{K} 30$ microbeads (Nayak et al., 2011). Incorporation of CMC with the alginate solution in presence of PVP/calcium chloride (F6) resulted in a significant reduction in the drug release rate with the formulation librating only $30.5 \%$ in the first 15 minutes with the rest of drug undergoing slow release throughout the course of the study (Figure 4). The release efficiency of the drug from this formulation was $69.65 \%$ (Table 2). This value was significantly lower than that recorded in absence of CMC $(\mathrm{P}<0.05)$. The presence of $\mathrm{CMC}$ in the beads added to the network structure of the beads and inforced the degree of crosslinking due to its interaction with calcium ions. This produces tight packing which disintegrate and dissociate slowly with subsequent slow release even in the intestinal phase (Jelvehgari et al., 2014)

Formulating CMC/alginate based beads in absence of PVP (F8) resulted in slow release profile of drug but the release rate was relatively faster than that of F6 (Figure 4). This formulation liberated $40.43 \%$ in the first 15 minutes with the release efficiency being $75.9 \%$ (Table 2). These results reflect a synergism between the effect of CMC and that of PVP.

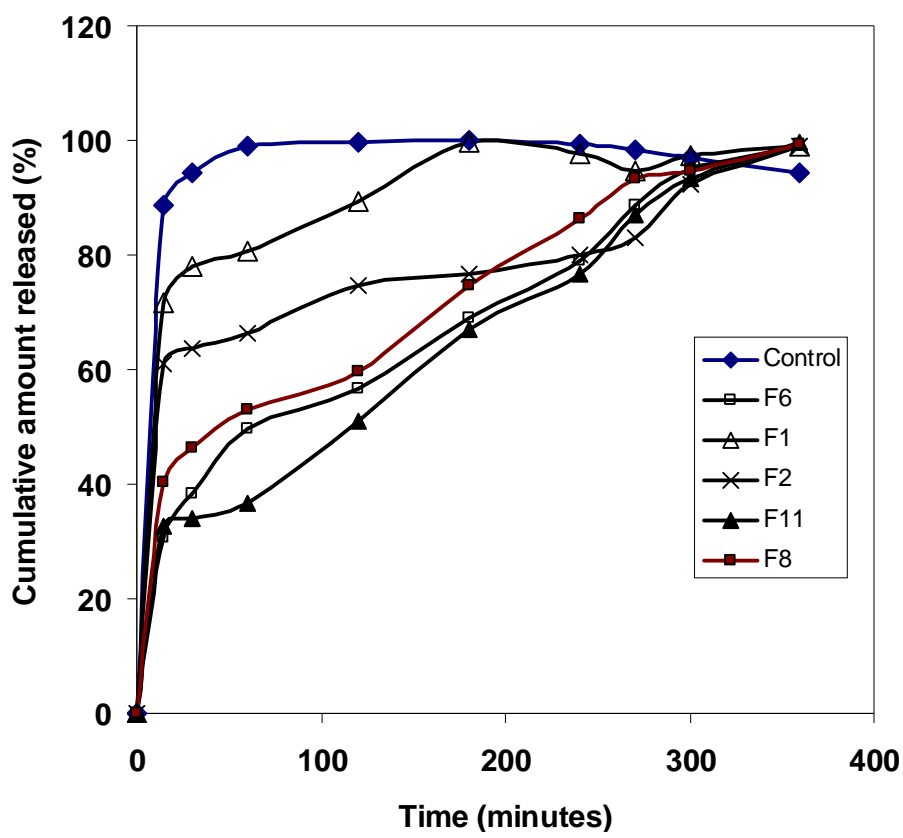

Fig. 4: Release of ambroxol hydrochloride from beads having different composition.

Incorporation of HPMC with alginate in the syringe and $\mathrm{PVP} /$ calcium chloride in the crosslinking solution (F11) produced beads capable of retaining the drug in the intestinal $\mathrm{pH}$. These beads showed relatively slower drug release pattern with the release efficiency reaching $65.9 \%$ (Figure 4 and Table 2). The reduction in the release rate in presence of HPMC can be explained on the bases of reduction of the porosity of the formulation in presence of HPMC. This polymer can form viscous microenvironment upon hydration with subsequent reduction in the release rate (Chowdary et al., 2009).

It is interesting to note that there was an inverse relationship between the entrapment efficiency and the release efficiency (Table 2). This indicates that the formulation showing high ability to retain the drug during the crosslinking step will have the same tendency to retain the drug during the release phase.

\section{CONCLUSION}

The specifications of alginate beads depend on the composition of the beads. Addition of viscosity modifiers increases the drug entrapment efficiency into these beads. PVP showed high potential for this due to filling of the surface pores of the beads with subsequent inhibition of drug loss during crosslinking. This effect was further enhanced after addition of either CMC or HPMC with those polymers improving the ability of the beads to control the rate of drug release both in the stomach and intestinal conditions.

\section{REFERENCES}

Al-Kassas R.S, Al-Gohary O.M, Al-Faadhel MM. Controlling of systemic absorption of gliclazide through incorporation into alginate beads. International Journal of Pharmaceutics, 2007; 341: 230-237.

Arica B, Calıs S, Kas H.S, Sargon M.F, Hincal A.A. 5Fluorouracil encapsulated alginate beads for the treatment of breast cancer. International Journal of Pharmaceutics, 2002; 242: 267-269.

Badarinath A.V, Ravi Kumar Reddy J, Mallikarjuna Rao K, Alagusundaram M, Gananprakash K, Madhu Sudhana Chetty C. Formulation and characterization of alginate microbeads of flurbiprofen by ionic gelation technique. International Journal of ChemTech Research, 2010; 2(1): 361-367.

Chowdary K.P.R, Sree Deepthi K, Srinivasa Rao Y. Mucoadhesive Microcapsules of Indomethacin: Evaluation for Controlled Release and Ulcerogenic Activity. International Journal of Pharmaceutical Sciences and Drug Research, 2009; 1(2): 74-79.

El Maghraby G.M, Alomrani A.H. Synergistic Enhancement of Itraconazole Dissolution by Ternary System Formation with Pluronic F68 and Hydroxypropylmethylcellulose. Sci Pharm, 2009; 77: 401-417.

El Maghraby G.M, El Zayat E.M, Al anazi F.K. Development of modified in situ gelling oral liquid sustained release formulation of dextromethorphan. Drug development and industrial pharmacy, 2012; 38(8): 971-978.

Goudanavar P.S, Pagali R.S, Chandrashekhara S. Design and characterization of diclofenac sodium microbeads by ionotropic gelation technique . International Journal of Pharma and Bio Sciences, 2010; 1(2): $1-10$.

Jelvehgari $M$, Valizadeh $H$, Motlagh $R$, Montazam $H$. Formulation and Physicochemical Characterization of Buccoadhesive Microspheres Containing Diclofenac Sodium. Advanced Pharmaceutical Bulletin, 2014; 4(3): 295-301.

Kanaka Durga Devi1 N, Chandana M, Sindhura A, Ratnavali1 G, Kavitha R. Comparative evaluation of alginate beads prepared by ionotropic gelation technique Pharmacophore, 2010;3(1): 196-213.

Kanjanabat S, Pongjanyakul T. Preparation and characterization of nicotine-magnesium aluminum silicate complex- 
loaded sodium alginate matrix tablets for buccal delivery. AAPS Pharm. Sci. Tech, 2011; 12: 683-692.

Karavas E, Georgarakis E, Bikiaris D. Application of PVP/HPMC miscible blends with enhanced mucoadhesive properties for adjusting drug release in predictable pulsatile chronotherapeutics. European Journal of Pharmaceutics and Biopharmaceutics, 2006; 64: 115126.

Karewicza A, Zasadaa K, Szczubiałkaa K, Zapotocznya S, Lach R, Nowakowskaa M. "Smart" alginate-hydroxypropylcellulose microbeads for controlled release of heparin. International Journal of Pharmaceutics, 2010; 385: 163-169.

Kassem M.A, El Assal M.I, Al-Badrawy A.A. Preparation and Evaluation of Certain Hydrophilic Drug-Loaded Microspheres . Int. Res. J. of Pharmaceuticals, 2012; 2(4): 82-90.

Kubo W, Miyazaki S, Dairaku M, Togashi M, Mikamib R, Attwood D. Oral sustained delivery of ambroxol from in situ-gelling pectin formulations. International Journal of Pharmaceutics, 2004; 271: 233-240.

Mandal S, Kumar S.S, Krishnamoorthy B, Basu S.K. Development and evaluation of calcium alginate beads prepared by sequential and simultaneous methods. Brazilian Journal of Pharmaceutical Sciences 2010; 46(4): 785-793

Narra K, Dhanalekshmi U, Rangaraj G, Raja D, Kumar C.S, Reddy P.N, Mandal A.B. Effect of Formulation Variables on Rifampicin Loaded Alginate Beads. Iranian Journal of Pharmaceutical Research, 2012; 11(3): 715-721.

Nayak A.K, Khatua S, Hasnain M.S, Sen K.K. Development of diclofenac sodium-loaded alginate-PVP K 30 microbeads using central composite design. DARU, 2011; 19 (5): 356-366.
Poncelet D, Babak V, Dulieu C, Picot A. A physico-chemical approach to production of alginate beads by emulsification-internal ionotropic gelation. Colloids Surfaces A: Physicochem Engineering Aspects, 1999; 155: 171-176.

Rajesh M, Narayan N, Chacko A. Formulation and evaluation of mucoad-hesive microcapsules of aceclofenac using methyl cellulose and carbopol asmucoadhesive polymers. Int. J. Pharm. Pharm. Sci., 2012; 4: 362-366.

Rangaraj G, Kishore N, Dhanalekshmi U.M, Raja M.D, Senthil Kumar C, Neelkanta Reddy P. Design and study of formulation variables affecting drug loading and its release from Alginate beads. J. Pharm. Sci. \& Res., 2010: 2(2): 77-81.

Rasel M.A, Hasan M. Formulation and Evaluation of Floating Alginate Beads of Diclofenac Sodium. Dhaka Univ. J. Pharm. Sci, 2012; 11(1): 29-35.

Saleem M.A, Murali Y.D, Naheed M.D, Jaydeep P, Dhaval M. Preparation and evaluation of valsartan loaded hydrogel beads.International research journal of pharmacy,2012;3(6): 80-85.

Takka S, Gürel A. Evaluation of Chitosan/Alginate beads using experimental design: Formulation and in vitro characterization .AAPS PharmSciTech, 2010: 11(1): 460-466.

\section{How to cite this article:}

Karam F. Abdalla, Elbadawy A. Kamoun, Gamal M. El Maghraby. Optimization of the entrapment efficiency and release of ambroxol hydrochloride alginate beads. J App Pharm Sci, 2015; 5 (04): 013019. 